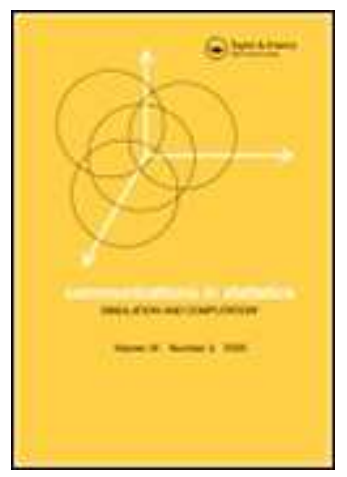

\title{
ANALYZING SMALL SAMPLES OF REPEATED MEASURES DATA WITH THE MIXED-MODEL ADJUSTED F TEST
}

\begin{tabular}{|c|c|}
\hline Journal: & Communications in Statistics - Simulation and Computation \\
\hline Manuscript ID: & LSSP-2008-0163.R2 \\
\hline Manuscript Type: & Original Paper \\
\hline $\begin{array}{l}\text { Date Submitted by the } \\
\text { Author: }\end{array}$ & 26-Jan-2009 \\
\hline Complete List of Authors: & $\begin{array}{l}\text { Arnau, Jaime; University of Barcelona, Metodología de las Ciencias } \\
\text { del Comportamiento } \\
\text { Bono, Roser; University of Barcelona, Metodología de las Ciencias } \\
\text { del Comportamiento } \\
\text { Vallejo, Guillermo; University of Oviedo }\end{array}$ \\
\hline Keywords: & $\begin{array}{l}\text { Kenward-Roger method, Linear mixed model, Repeated measures, } \\
\text { Type I error rate, Simulation }\end{array}$ \\
\hline Abstract: & $\begin{array}{l}\text { This research examines the Type I error rates obtained when using } \\
\text { the mixed model with the Kenward-Roger correction and compares } \\
\text { them with the Between-Within and Satterthwaite approaches in } \\
\text { split-plot designs. A simulated study was conducted to generate } \\
\text { repeated measures data with small samples under normal } \\
\text { distribution. The data were obtained via three covariance matrices } \\
\text { (unstructured, heterogeneous first-order auto-regressive and } \\
\text { random coefficients), the one with the best fit being selected } \\
\text { according to the Akaike criterion. The results of the simulation } \\
\text { study showed the Kenward-Roger test to be more robust, } \\
\text { particularly when the population covariance matrices were } \\
\text { unstructured or heterogeneous first-order auto-regressive. }\end{array}$ \\
\hline
\end{tabular}




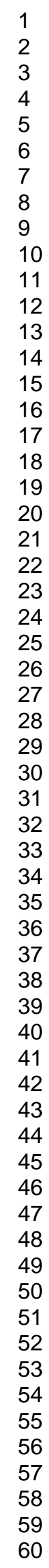

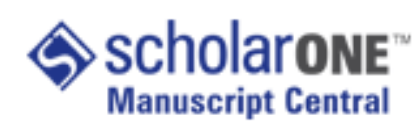
7 


\author{
ANALYZING SMALL SAMPLES OF REPEATED MEASURES DATA WITH THE \\ MIXED-MODEL ADJUSTED F TEST
}

\author{
Jaime Arnau \\ University of Barcelona \\ Roser Bono \\ University of Barcelona \\ Guillermo Vallejo \\ University of Oviedo
}

Running head: ANALYZING SMALL SAMPLES OF REPEATED MEASURES DATA

Received July 16, 2008

Correspondence concerning this article should be addressed to Roser Bono, Departamento de Metodología de las Ciencias del Comportamiento, Facultad de Psicología, Universidad de Barcelona, Passeig de la Vall d'Hebron 171, 08035Barcelona, Spain; e-mail: rbono@ub.edu 
Abstract

This research examines the Type I error rates obtained when using the mixed model with the Kenward-Roger correction and compares them with the Between-Within and Satterthwaite approaches in split-plot designs. A simulated study was conducted to generate repeated measures data with small samples under normal distribution conditions. The data were obtained via three covariance matrices (unstructured, heterogeneous first-order auto-regressive and random coefficients), the one with the best fit being selected according to the Akaike criterion. The results of the simulation study showed the Kenward-Roger test to be more robust, particularly when the population covariance matrices were unstructured or heterogeneous first-order autoregressive. The main contribution of this study lies in showing that the Kenward-Roger method corrects the liberal Type I error rates obtained with the Between-Within and Satterthwaite approaches, especially with positive pairings between group sizes and covariance matrices.

Key words: Kenward-Roger method; Linear mixed model; Repeated measures; Type I error rate; Simulation. 
1. Introduction

Over the last fifteen years researchers have shown a growing interest in the analysis of repeated measures data in both experimental and longitudinal contexts. In the former the main objective aim is to analyse treatment effects, while in the latter the idea is to test the effect across time longitudinal studies interest lies in testing the time effect. In both cases the difficulty arises when applying traditional analytic procedures such as analysis of variance (ANOVA) or multivariate analysis of variance (MANOVA).

One of the recent approaches to the analysis of repeated measures data is based on the mixed model (Littell et al., 1996). Laird and Ware (1982) established the bases of the linear mixed model, which takes into account the possible correlation of withinsubject errors. Subsequently, Cnaan et al. (1997) and Verbeke and Molenberghs (2000) reported a more complete specification and applied the multilevel model to longitudinal repeated measures data. Unlike wriance based analyses (ANOVA and MANOVA) the mixed model enables the structure of the covariance matrix to be specified on the basis of the data, rather than presupposing it. Thus, a more efficient estimate of the fixed effects is achieved and, consequently, more powerful statistical tests are obtained. This analysis can be performed using the PROC MIXED program of the SAS system (SAS Institute, 2000, 2004), which incorporates all the advantages of mixed model methodology with repeated measures data (Littell et al., 1998; Verbeke and Molenberghs, 1997). By means of this methodology the researcher models the covariance structure and achieves greater robustness when estimating the effects of repeated measures and interaction. 
Various studies have reported that the mixed model offers better control of Type I error, despite the fact, as Wright and Wolfinger (1996) point out, that Type I error may show a positive bias with incorrect covariance structures and small sample sizes. Keselman et al. (1999a) applied the mixed model with degrees of freedom based on the residual variance, which are the same as the degrees of freedom of the conventional $F$ test. These authors found that when the covariance matrix is not spherical the degrees of freedom associated with the conventional $F$ test are too large. One alternative would thus be to apply the procedure developed by Satterthwaite (1941) to adjust the degrees of freedom.

The problem with estimating the fixed effects of the repeated-measures factor and the interaction with the group factor arises from the misspecification of the covariance matrix, especially when sample sizes are small. The PROC MIXED program of SAS includes several options for model specification with which it is possible to change the degrees of freedom when estimating these effects. In general, the inferences obtained with the PROC MIXED program of SAS are based on the Wald test, which is valid with large samples. Keselman et al. (1999b) point out that the Satterthwaite approach has only recently been applied to covariance structures and it is still not entirely clear how the mixed model works. The degrees of freedom with the Satterthwaite correction are more conservative than the residual degrees of freedom and they can be expected to yield more precise $F$ tests. This is the conclusion reached in the study by (Keselman et al., (1999a), which showed the $F$ test to be much more liberal when the degrees of freedom were based on residuals.

The present study applied the mixed model (by means of SAS PROC MIXED, version 9.1.3) to compare tests of the fixed effects of repeated measures and the 
interaction in split-plot designs using three degrees-of-freedom solutions: BetweenWithin (BW), Satterthwaite (SW) and Kenward-Roger (KR). Although the small sample distribution of Wald statistics is approximated by an may yield geod approximations of the value of $F$ with small samples distribution (Kendward and Roger, 1997), the statistical results are generally rather poor. The properties of small samples can be improved by using the Satterthwaite approach to denominator degrees of freedom (Satterthwaite, 1941), or through the Kenward-Roger adjusted degrees of freedom solution (Kenward and Roger, 1977).

Keselman et al. (1999b) found that $F$ tests combined with the Satterthwaite approach, using PROC MIXED, were as robust as default tests when the true structure of the covariance matrix was specified. Keselman et al. (1999a) based the degrees of freedom of the mixed model on the variance of the residuals, which coincide with the degrees of freedom of the error of the conventional $F$ test. Through its MODEL option the PROC MIXED program enables researchers to use the $F$ approximation based on the solution given by Satterthwaite (1946). This approximation corrects the degrees of freedom for the test of fixed effects of repeated measures, and was investigated by Keselman et al. (1999b) to determine its efficacy in controlling Type I error. However, tests of the fixed effects of repeated measures using PROC MIXED were more robust when the true covariance structure was known. With versions 8 and above of SAS it is possible to use the Kenward-Roger solution (Kenward and Roger, 1997) as an alternative way of calculating the degrees of freedom. This procedure appears to yield more accurate results of inferences for the fixed effects with small samples (Kowalchuk et al., 2004; Schaalje et al., 2001). 
1.1. Satterthwaite and Kenward-Roger approximations for correcting degrees of freedom

Assuming that statistical tests follow an approximate distribution of $F$ with the corresponding calculation of the degrees of freedom, SAS PROC MIXED (version 9.1.3) now incorporates two methods for correcting this calculation. The sample distribution of $F$ approximately follows an $F$ distribution with $q$ and $v$ as degrees of freedom in the numerator and denominator of this ratio. When using the residual degrees of freedom, $n$ rank $(\mathbf{X})$, where $n$ is the number of observations, the results obtained are too liberal. Hence it is better to use the two approaches for correcting degrees of freedom that are incorporated into SAS PROC MIXED: DDFM=SATTERTH and DDFM=KENWARDROGER. Given the above, the present study aimed to compare the mixed-model procedure using the Satterthwaite and Kenward-Roger solutions for degrees of freedom with the system that separates the between and within degrees of freedom with small samples.

The Satterthwaite approximation is a generalization of techniques proposed by Giesbrecht and Burns (1985), McLean and Sanders (1988) and Fai and Cornelius (1996). Let $\boldsymbol{\theta}$ be a vector of unknown parameters in $\mathbf{V}$ (variance/covariance matrix) and $\mathbf{C}=\left(\mathbf{C}^{\prime} \mathbf{V}^{-1} \mathbf{X}\right)^{-}$, where ${ }^{-}$denotes a generalized inverse. If $\hat{\mathbf{C}}$ and $\hat{\boldsymbol{\theta}}$ are the corresponding estimates, the denominator degrees of freedom can be calculated by performing the spectral decomposition $\mathbf{L} \hat{\mathbf{C}} \mathbf{L}$ ' $=\mathbf{P}$ 'DP, where $\mathbf{P}$ is an orthogonal matrix of eigenvectors and $\mathbf{D}$ is a diagonal matrix of eigenvalues, both of dimension $q \times q$. Define $l_{m}$ as the $m$ th row of PL and let 


$$
v_{m}=\frac{2\left(D_{m}\right)^{2}}{g_{m}^{\prime} \mathbf{A} g_{m}}
$$

where $D_{\mathrm{m}}$ is the $m$ th diagonal element of $\mathbf{D}$ and $g_{m}$ is the gradient of $l_{m} \mathbf{C} l^{\prime}{ }_{m}$ with respect to $\boldsymbol{\theta}$, evaluated at $\hat{\boldsymbol{\theta}}$. A is the asymptotic variance-covariance matrix of $\hat{\boldsymbol{\theta}}$ obtained from the second derivative matrix of the likelihood equations. Thus

$$
\mathrm{E}=\sum_{m=1}^{q} \frac{v_{m}}{v_{m}-2} \mathbf{I}\left(v_{m}>2\right)
$$

where the indicator function eliminates terms for which $v_{m} \leq 2$. The degrees of freedom for $F$ are then given by

$$
v=\frac{2 \mathrm{E}}{\mathrm{E}-q}
$$

provided $\mathrm{E}>q$; otherwise $v=0$.

The Kenward-Roger approximation calculates the degrees of freedom in a similar way and is used for tests with mixed linear models based on any covariance structure. If $\mathbf{C}$ is a contrast matrix of range $q$, the Wald $F$ for the hypothesis $\mathrm{H}_{0}: \mathbf{C} \boldsymbol{\beta}=0$ is given by $F=\mathrm{W} / q$, where

$$
\mathrm{W}=(\mathbf{C} \hat{\boldsymbol{\beta}})^{\prime}\left(\mathbf{C}\left(\mathbf{X}^{\prime} \hat{\mathbf{V}}^{-1} \mathbf{X}\right)^{-1} \mathbf{C}^{\prime}\right)^{-1}(\mathbf{C} \hat{\boldsymbol{\beta}})
$$

The next step is to calculate a scale factor $\delta$ and an approximate value of the degrees of freedom $v$. Thus, the Kenward-Roger $F$ statistic is given by

$$
F^{*}=\delta F_{\mathrm{KR}}
$$

where $F_{\mathrm{FR}}=\frac{1}{q}(\mathbf{C} \hat{\boldsymbol{\beta}})^{\prime}\left(\mathbf{C}\left(\mathbf{X}^{\prime} \hat{\mathbf{V}}^{-1} \mathbf{X}\right)^{-1} \mathbf{C}^{\prime}\right)^{-1}(\mathbf{C} \hat{\boldsymbol{\beta}})$. The moments of $F^{*}$ are then generated and equated to the moments of the $F$ distribution to solve for $\delta$ and $v$. Under a null hypothesis it is assumed that $F^{*}$ is approximately distributed as $F$ with $q$ degrees of freedom in the numerator and $v$ degrees of freedom in the denominator. Thus, two 


$$
\delta=\frac{v}{\mathrm{E}\left[F_{\mathrm{KR}}\right](v-2)}
$$

The degrees of freedom are calculated in a similar way to that used in the previous procedure and the Wald $F$ statistic is adjusted to take into account the bias associated with small samples and the variability of the estimated variance matrix.

The inferences derived from simulation studies using these methods usually function well, even with complex covariance structures (Keselman et al., 1998; Schaalje et al., 2002). In the present study we compared the functioning of these models with normally-distributed small samples and covariance structures that violate the assumption of sphericity, a situation that occurs frequently in the context of longitudinal repeated measures. It has been demonstrated that in the case of normally-distributed data and heterogeneous within-group covariance structures the KR procedure meets the criterion of robustness (Livacic-Rojas et al., 2006). The aim of the present study was thus to determine the functioning of heterogeneous covariance structures, both across groups and within measurement occasions, when estimating estimate the fixed effects associated with time and their interaction with relatively small samples in split-plot designs, using mixed models. This approach enables users to model the covariance 
structure for subjects for a repeated measures variable, and also allows them to fit different covariance structures to each group of subjects for each level of a betweensubjects grouping variable.

\section{Simulation method}

The split-plot design includes a between-subjects factor, where the subjects $\left(i=1, \ldots, n_{j}\right)$ are chosen at random for each group $(j=1, \ldots, J)$, and a within-subjects factor of repeated measures $(k=1, \ldots, K)$. The main objective of this type of design is to study the main repeated measures effect and the group x repeated measures interaction. Here it is assumed that the $\left(y_{i j k}\right)$ data are normally distributed. The test statistics for the effects are based on the covariance structure selected by the Akaike Information Criterion (AIC).

\subsection{Study variables}

The statistical tests of the main repeated measures effect, as well as of the interaction with the group factor, have been conducted with both balanced and unbalanced designs, with a between-subjects factor and a within-subjects factor. Three values levels were taken used for the between-subjects factor, while the values levels four, six and eight levels were used for the within-subjects factor. In the simulation study the combinations of five variables were selected for each level value of $K$ : a) covariance structure of the population; b) homogeneous and heterogeneous between-group covariance structures; c) total sample size; d) equal and unequal group sizes; and e) pairings of the covariance matrices and group sizes. 
Three covariance structures with within-subject heterogeneity were used to generate the simulated data: unstructured (UN), heterogeneous first-order autoregressive (ARH), and random coefficients (RC). At the same time we investigated whether the assumption of sphericity was violated, taking the indices $\varepsilon=0.57$ and 0.75 . When $\varepsilon=1$, the assumption of sphericity is met with designs $J$ x $K$, whereas with $\varepsilon=$ $1 /(K-1)$ the index takes the extreme value. Most studies use a value of 0.75 as a good approximation of sphericity, and 0.57 as indicative of non-sphericity (Algina and Keselman, 1998; Keselman et al., 1999a; Lix et al., 2003). Table 1 shows the values of the covariance matrices for the corresponding sphericity indices. We have omitted the values of the generating covariance matrices corresponding to structures of six and eight repeated measures.

[Table 1. Insert here approximately]

Of the eighteen covariance structures generated we analysed both the equal and unequal between-group covariance matrices. With heterogeneous matrices the inequality of the groups fitted followed the ratio 1:3:5, as in the studies by Keselman et al. (1993), Vallejo et al. (2001), Lix et al. (2003), Livacic-Rojas et al. (2006), and Vallejo and Ato (2006). Thus, $\Sigma_{1}={ }_{1}^{1} \Sigma_{3} \Sigma_{2}$ and $\Sigma_{3}=\frac{5}{3} \Sigma_{2}$, where $\Sigma_{j}$ is the covariance matrix for group $j$. In addition, we investigated the conditions of equality and inequality for group size, considering total sample sizes of $N=30,36$ and 42. Equal and unequal group sizes were taken for each value of $N$. In the latter case we chose group sizes that represented values of the variance coefficient of the group size, $\Delta n_{j}=0.41$, and when the group sizes were equal $\Delta n_{j}=0$. With $\Delta n_{j}=0.41$, the unequal group sizes were: a) 5 , 
$10,15(N=30)$; b) $6,12,18(N=36)$; and c) $7,14,21(N=42)$. With $\Delta n_{j}=0$, the equal group sizes were: a) 10, 10, $10(N=30)$; b) 12, 12, $12(N=36)$; and c) $14,14,14(N=$ 42). Finally, we defined the type of pairing between group sizes and covariance matrix. Positive pairing associates the sample of the larger group with the covariance matrix whose values are larger. In contrast, negative pairing relates combines the largest group size with the covariance matrix comprised of smaller elements. In the case of balanced designs, pairing is null.

Table 2 summarises the various combinations of variables examined in the present study. For each combination, 1000 replications were performed at a significance level of 0.05: $K$ x covariance structures x $\varepsilon$ x combinations $N\left(n_{1} n_{2} n_{3}\right) / \Delta n_{j} /$ betweengroup covariances/pairing $\times$ replications $(3 \times 3 \times 2 \times 12=216$ simulation conditions). For the simulations we studied the main effect of the repeated measures variable and the interaction with the group variable when the data were normally distributed.

[Table 2. Insert here approximately]

The simulation data were generated by means of a macro from SAS 9.1.3 (SAS Institute, 1997) and using the programming language IML (Interactive Matrix Language), also from SAS (SAS Institute, 1999a). The first step involved generating the covariance matrices from variances and correlations for values of $\varepsilon=0.57$ and $\varepsilon=0.75$. Next, the RANNOR generator of SAS (SAS Institute, 1999b) was used to derive normally-distributed pseudorandom observations by means of the Cholesky factor of the covariance matrix $\boldsymbol{\Sigma}_{j}$. Finally, each set of data was analysed with PROC MIXED (SAS Institute, 2000, 2004), using the covariance structure selected according to the 
Akaike Information Criterion(AIC). The DDFM options in the MODEL statement were BETWITHIN, SATTERTH and KENWARDROGER. The TYPE statement was used to specify the covariance structure which showed the best fit according to the AIC.

\subsection{Covariance structures adjusted to the data}

Given the possibility of heterogeneity, both within and between subjects, eleven covariance structures were fit with PROC MIXED applying the AIC criteria, the aim being to select the one with the lowest value. The following covariance matrices were fit: a) compound symmetry (CS); b) unstructured (UN); c) first-order autoregressive (AR); d) Huynh-Feldt spherical (HF); e) within-subjects heterogeneous compound symmetry (CSH); f) within-subjects heterogeneous first-order autoregressive (ARH); g) random coefficients $(\mathrm{RC}) ; \mathrm{h})$ between-subjects heterogeneous unstructured $\left(\mathrm{UN}_{j}\right)$; i) between-subjects heterogeneous Huynh-Feldt spherical $\left.\left(\mathrm{HF}_{j}\right) ; \mathrm{j}\right)$ within- and betweensubjects heterogeneous first-order autoregressive $\left(\mathrm{ARH}_{j}\right)$; and $\left.\mathrm{k}\right)$ between-subjects heterogeneous random coefficients $\left(\mathrm{RC}_{j}\right)$, where the subscript $j$ indicates that the covariance matrices are not equal between the groups.

\section{Results}

In an initial simulation study we analysed examined the covariance structure selected by the AIC from among the eleven covariance 11 structures (CS, UN, AR, HF, CSH, ARH, $\mathrm{RC}, \mathrm{UN}_{j}, \mathrm{HF}_{j}, \mathrm{ARH}_{j}$ and $\mathrm{RC}_{j}$ ). A second study was then conducted to calculate the $p$ values for tests of fixed effects, taking into account the covariance structure selected by 
AIC, and the different methods used to adjust the degrees of freedom (BW, SW and $\mathrm{KR})$.

\subsection{Selecting the covariance structure}

The AIC was used as the fit criterion due to its advantages over the Schwarz's Bayesian Information Criterion (BIC). Keselman et al. (1998) demonstrated that the AIC chooses the population covariance structure on $47 \%$ of occasions, while the BIC achieved a rate of $35 \%$. Similarly, Ferron et al. (2002) showed that the AIC selects the true covariance structure on $79 \%$ of occasions, compared to a rate of $66 \%$ for the BIC. More recently, Vallejo and Livacic-Rojas (2005) reported that the results of tests based on the AIC are better at controlling Type I error rates than are those based on the BIC. These authors found that with the BIC, PROC MIXED offers poor control over the estimated probabilities of Type I error. Gomez et al. (2005) concluded that the AIC has a better success rate with complex covariance structures, for example, UN. More recently, Vallejo et al. (2008) found that with different group sizes the AIC is better at estimating standard errors. Given these findings we conducted a simulation study using the AIC. However, it should be remembered that the Akaike criterion does not always select the enly true structure, since and other structures may also provide adequate approximations.

Tables 3, 4 and 5 show which of the eleven candidate covariance structures are selected most often by the AIC the fit percentages of the eleven matrices to the eovariance structures generated, according to the different combinations of variables studied. It should be noted that with homogeneous between-groups covariances we used 
the population matrices $\mathrm{UN}, \mathrm{ARH}$ and $\mathrm{RC}$, while $\mathrm{UN}_{j}, \mathrm{ARH}_{j}$ and $\mathrm{RC}_{j}$ were used with heterogeneous covariances.

\subsubsection{Homogeneity of covariances}

In general it can be seen that with homogeneous covariances the structures showing the best fit are the same as the true UN (Table 3) and ARH (Table 4), with some exceptions when $\varepsilon=0.75$. With UN matrices the percentages oscillate between $63.3 \%$ and $84.3 \%$ (Table 3), and with ARH matrices between $46.7 \%$ and $88.6 \%$ (Table 4). In contrast, with RC covariance matrices the fit percentages of the true structure are practically null (Table 5), the most frequently selected structure being CSH (40-76.3\%).

\subsubsection{Heterogeneity of covariances}

It can be seen in Table 3 shows that with heterogeneous covariance matrices and when UN is the true structure, the structures that-show the best fit to UN are selected most often are $\mathrm{UN}_{j}(53.70 .0-77.5 \%)$ and $\mathrm{ARH}_{j}(46.73 .0-62.3 \%)$. When the covariance matrix is $\mathrm{ARH}$ (Table 4) the most frecuently frequently selected $\mathrm{ARH}_{j}$ covariance structure is selected more often $\mathrm{ARH}_{j}(56.5-97.3 \%)$. However, with $K=8$ and $\varepsilon=0.75$ another pattern emerges: with homogeneity of groups the best fitting most selected matrix is $\mathrm{UN}_{j}$ (90\%), while with positive and negative pairings the best-fitting most selected matrix is $\mathrm{UN}(88.3 \%$ and $79.3 \%$, respectively).

With RC covariance matrices, several structures show a eorrect fit higher percentage fit (Table 5). Thus, when the covariance matrices are heterogeneous the fit 
of the $\mathrm{UN}_{j}$ matrix oscillates between $27.3 \%$ and $87.9 \%$, while the fit of the $\mathrm{ARH}_{j}$ matrix is in the range $34.6-52 \%$. The $\mathrm{RC}_{j}$ structure only shows the best fit when $K=6, \varepsilon=0.57$ and there is positive pairing $(35.5 \%)$.

[Table 3. Insert here approximately]

[Table 4. Insert here approximately]

[Table 5. Insert here approximately]

\subsection{Type I error rates}

The present study followed the criterion of Bradley (1978), by which a test is robust if the empirical error rate is within the range $0.025-0.075$ for $\alpha=0.05$. A test is considered to be liberal when the empirical Type I error rate exceeds the upper limit. In contrast, when the error rate is below the lower limit the test is conservative. According to Kowalchuk et al. (2004) it is important that applied researchers use procedures that control the Type I error rate within the limits established by Bradley (1978), particularly when these procedures must assume a series of violation conditions.

Tables 6-11 show the empirical Type I error rates according to the combination of the different variables indicated in Table 2, with respect to the population covariance structure. Bold entries correspond to values above the established upper limit while those in italics indicate values below the lower limit.

\subsection{7 sphericity}


The values shown in Tables 6 and 7 indicate that the KR test is more robust than the BW and SW tests. However, if the simulated covariance structure is UN (Table 6) the KR method is liberal with negative pairing $(0.077-0.272)$. It can be seen that when the number of repeated measures increases to $K=8$ the KR procedure remains robust even with negative pairing. Table 7 shows that when the simulated covariance structure is ARH the KR method may still be is sometimes robust with negative pairing, even with $K=4$ and $K=6$. Finally, Table 8 depicts the results for RC simulated covariance matrices. Note that in comparison to the other covariance structures the tests are conservative when $K$ increases and pairing is positive. In this case the KR method often does not correct the Type I error rate.

[Table 6. Insert here approximately]

[Table 7. Insert here approximately]

[Table 8. Insert here approximately]

\subsection{5 sphericity}

For the more spherical covariance structures, when the population covariance structure is UN (Table 9) or ARH (Table 10) the KR test is more robust, although it is difficult for Type I error rates to approach nominal values with negative pairing. This is particularly so with the effect of the interaction effect. In these cases the KR test is liberal. With an ARH structure, positive pairing and $K=8$ the tests tend to be more conservative, especially as regards the time effect (Table 10). With respect to the RC structure (Table 11) the Type I error rates are much higher than the nominal value with negative pairings. Furthermore, when the BW and SW tests are more conservative with 
positive pairings, the same Type I error rate is obtained with the KR method. This is observed to a greater extent with the time effect.

[Table 9. Insert here approximately]

[Table 10. Insert here approximately]

[Table 11. Insert here approximately]

\section{Discussion}

This research aimed to assess the robustness of the BW, SW and KR procedures in split-plot designs with small numbers of subjects per groups. The first simulation study enabled us to select the covariance matrices with the best fit according to the AIC, thus taking into account any possible bias due to a wrong choice, which would affect the robustness of the statistical test used (Vallejo et al., 2008). With homogeneous covariances we found that the true $\mathrm{UN}$ and $\mathrm{ARH}$ structures showed a high fit percentage. However, this was not the case for RC covariance matrices, where the fit percentages of the true structure were close to zero. When the covariance matrices were heterogeneous, several structures, in addition to the true one, showed a high fit percentage.

As reported by Keselman and Keselman (1990) we found that heterogeneous covariance matrices produce a greater discrepancy between empirical and nominal Type I error rates. Some research has suggested that the mixed model with BW or SW degrees of freedom increases Type I error rates when the between-groups covariance matrices are heterogeneous and sample sizes are small, even when the groups are equal 
in size (Keselman et al., 1999a, 1999b; Keselman et al., 2000; Wright and Wolfinger, 1996). This effect is heightened in the case of negative pairings. For example, Keselman et al. (1999b) found that the empirical Type I error rate when using the SW adjustment reached $8 \%$ when testing the main repeated-measures effect and $9.9 \%$ when testing the interaction effect.

In accordance with the studies of Kowalchuk et al. (2004) and Vallejo and Ato (2006) we conclude that in many cases when the covariance structure selected by AIC is applied the KR test of PROC MIXED enables, in many cases, Type I error rates to be controlled. However, our results indicate that with negative pairings the KR method tends to be liberal, while with positive pairings it proves to be conservative in some cases. Similar results were reported by Vallejo and Livacic-Rojas (2005) and Vallejo and Ato (2006) when estimating Type I error rates with normally-distributed data. Furthermore, in our study, with the non-spherical covariance matrices UN, ARH and $\mathrm{RC}$ we found that the KR method may be acceptable even with negative pairing. Gomez et al. (2005) found no evidence that negative pairings had an adverse effect on Type I error rates for the within-subject effect. In fact, they observed that for tests of time effect, negative pairing produced slightly better Type I error rates than did positive pairing. Our study could not confirm this conclusion because we did not generate the same covariance structures.

In general, this study enables the following conclusions to be drawn: a) Type I error rates are inflated liberal even when using the true covariance structure selected by the AIC in the analysis; b) on most occasions the Type I error rates observed for the interaction effect are higher than those for the main effect; c) the SW method is more robust than the $\mathrm{BW}$ procedure, and the $\mathrm{KR}$ approximation is more robust than the $\mathrm{SW}$ 
method; d) the BW and SW tests are more liberal; e) the tests are scarcely robust with negative pairing; f) with positive pairing and $\mathrm{ARH}$ or RC covariance structures the tests may be conservative; and g) the best outcomes with the KR test are achieved with UN or ARH structures and $\varepsilon=0.57$.

In sum, the main contribution of this study is to confirm that PROC MIXED with the KR correction offers the best control of Type I error rates in most of the conditions studied, particularly when the BW and SW tests are liberal with positive pairings.

Acknowledgements

This research was supported by Grants MEC-SEJ2005-01923 and MEC-SEJ200501883 from Spain's Ministry of Education and Science. 
References

Algina, J., Keselman, H. J. (1998). A power comparison of the Welch-James and Improved General Approximation tests in the split-plot design. Journal of Educational and Behavioral Statistics 23:152-169.

Bradley, J. V. (1978). Robustness? British Journal of Mathematical and Statistical Psychology 31:144-152.

Cnaan, A., Laird, N. M., Slasor, P. (1997). Using the general linear mixed model to analyze unbalanced repeated measures and longitudinal data. Statistics in Medicine 16:2349-2380.

Fai, A. H. T., Cornelius, P. L. (1996). Approximate F-tests of multiple degree of freedom hypotheses in generalized least squares analyses of unbalanced split-plot experiments. Journal of Statistical Computing and Simulation 54:363-378.

Ferron, J., Dailey, R., Yi, Q. (2002). Effects of misspecifying the first-level error structure in two-level models of change. Multivariate Behavior Research 37:379403.

Giesbrecht, F. G., Burns, J. C. (1985). Two-stage analysis based on a mixed model: large-sample asymptotic theory and small-sample simulation results. Biometrics $41: 853-862$.

Gomez, E. V., Schaalje, G. B., Fellingham, G. W. (2005). Performance of the KenwardRoger method when the covariance structure is selected using AIC and BIC. Communication in Statistics-Theory and Methods 34:377-392.

Kenward, M. G., Roger, J. H. (1997). Small sample inference for fixed effects from restricted maximum likelihood. Biometrics 53:983-997. 
Keselman, H. J., Algina, J., Kowalchuk R. K., Wolfinger, R. D. (1998). A comparison of two approaches for selecting covariance structures in the analysis of repeated measurements. Communications in Statistics Simulation and Computation 27:591604.

Keselman, H. J., Algina, J., Kowalchuk R. K., Wolfinger, R. D. (1999a). A comparison of recent approaches to the analysis of repeated measurements. British Journal of Mathematical and Statistical Psychology 52:63-78.

Keselman, H. J., Algina, J., Kowalchuk, R. K., Wolfinger, R. D. (1999b). The analysis of repeated measurements: A comparison of mixed-model Satterthwaite $F$ tests and a nonpooled adjusted degrees of freedom multivariate test. Communication in Statistics-Theory and Methods 28: 2967-2999.

Keselman, H. J., Carriere, K. C., Lix, L. M. (1993). Testing repeated measures hypotheses when covariance matrices are heterogeneous. Journal of Educational Statistics 18:305-319.

Keselman, J. C., Keselman, H. J. (1990). Analysing unbalanced repeated measures designs. British Journal of Mathematical and Statistical Psychology 43:265-282.

Keselman, H. J., Kowalchuk, R. K., Algina, J., Lix, L. M., Wilcox, R. R. (2000). Testing treatment effects in repeated measures designs: Trimmed means and bootstrapping. British Journal of Mathematical and Statistical Psychology 53: 175191.

Kowalchuk, R. K., Keselman, H. J., Algina, J., Wolfinger, R. D. (2004). The analysis of repeated measurements with mixed-model adjusted $F$ tests. Educational and Psychological Measurement 64:224-242. 
Laird, N. M., Ware, J. H. (1982). Random effects models for longitudinal data. Biometrics 38:963-974.

Littell, R. C., Henry, P. R., Ammerman, C. B. (1998). Statistical analysis of repeated measures data using SAS procedures. Journal of Animal Science 76:1216-1231.

Littell, R. C., Milliken, G. A., Stroup, W. W., Wolfinger, R. D. (1996). SAS System for Mixed Models. Cary, NC: SAS Institute.

Livacic-Rojas, P., Vallejo, G., Fernández, P. (2006). Procedimientos estadísticos alternativos para evaluar la robustez mediante diseños de medidas repetidas. Revista Latinoamericana de Psicología 38:579-599.

Lix, L. M., Algina, J., Keselman, H. J. (2003). Analyzing multivariate repeated measures designs: A comparison of two approximate degrees of freedom procedures. Multivariate Behavioral Research 38:403-431.

McLean, R. A., Sanders, W. L. (1988). Approximating degrees of freedom for standard errors in mixed linear models. Proceedings of the Statistical Computing Section, American Statistical Association. New Orleans, LA.

SAS Institute. (1997). SAS Macro language: Reference. Cary, NC: SAS Institute.

SAS Institute. (1999a). SAS/IML Software, usage and reference, Version 8. Cary, NC: SAS Institute.

SAS Institute. (1999b). SAS Language reference: Dictionary, Version 8. Cary, NC: SAS Institute.

SAS Institute. (2000). SAS/STAT User's guide, Version 8. Cary, NC: SAS Institute.

SAS Institute. (2004). SAS Online Doc 9.1.3. Cary, NC: SAS Institute.

Satterthwaite, F. E. (1941). Synthesis of variance. Psychometrika 6:309-316. 
Satterthwaite, F. E. (1946). An approximate distribution of estimates of variance components. Biometrics Bulletin 2:110-114.

Schaalje, G. B., McBride, J. B., Fellingham, G. W. (2001). Approximations to distributions of test statistics in complex mixed linear models using SAS Proc MIXED, SUGI 26 Proceedings, Statistics, Data Analysis and Data Mining Section, Paper 262-26. Consulted on 15 November 2007 at: http://www2.sas.com/proceedings/sugi26/proceed.pdf.

Schaalje, G. B., McBride, J. B., Fellingham, G. W. (2002). Adequacy of approximations to distributions of test statistics in complex mixed linear models, Journal of Agricultural Biological and Environmental Statistics 7:512-524.

Vallejo, G., Ato, M. (2006). Modified Brown-Forsythe procedure for testing interactions effects in split-plot designs. Multivariate Behavioral Research 41:549578.

Vallejo, G., Ato, M., Valdés, T. (2008). Consequences of misspecifying the error covariance structure in linear mixed models for longitudinal data. Methodology. European Journal of Research for the Behavioral and Social Sciences 4:10-11.

Vallejo, G., Fidalgo, A., Fernández, P. (2001). Effects of covariance heterogeneity on three procedures for analyzing multivariate repeated measures designs. Multivariate Behavioral Research 36:1-27.

Vallejo, G., Livaci-Rojas, P. (2005). Comparison of two procedures for analyzing small sets of repeated measures data. Multivariate Behavioral Research 40:179-205.

Verbeke, G., Molenberghs, G. (1997). Linear Mixed Models in Practice: A SASoriented Approach. New York: Springer-Verlag. 
Verbeke, G., Molenberghs, G. (2000). Linear Mixed Models for Longitudinal Data. New York: Springer-Verlag.

Wright, S. P., Wolfinger, R. D. (1996, October). Repeated measures analysis using mixed models: Some simulation results. Paper presented at the Conference on Modelling Longitudinal and Spatially Correlated Data: Methods, Applications, and Future Directions, Nantucket, MA. 
Table 1. Population covariance matrices.

\begin{tabular}{|c|c|c|c|c|c|c|c|c|c|c|c|}
\hline \multicolumn{4}{|c|}{ UN } & \multicolumn{4}{|c|}{ ARH } & \multicolumn{4}{|c|}{$\mathrm{RC}$} \\
\hline 1 & 1.60000 & 1.80000 & 2.32379 & 1 & 1.5800000 & 1.8723000 & 1.9095318 & T9 & 13 & 18 & 23 \\
\hline & 4 & 4.80000 & 4.64758 & & 4 & 4.7400000 & 4.8342578 & & 27.7 & 34.4 & 45.1 \\
\hline & & 9 & 9.29516 & & & 9 & 9.1789705 & & & 59.8 & 67.2 \\
\hline & & & 15 & & & & 15 & & & & 104.3 \\
\hline \multicolumn{4}{|c|}{$\varepsilon=0.57$} & \multicolumn{4}{|c|}{$\varepsilon=0.57$} & \multicolumn{4}{|c|}{$\varepsilon=0.57$} \\
\hline & 1.6391 & 1.7913 & 3.7038 & 2 & .2449490 & 0.0424264 & 0.0054772 & {$[1.30$} & 0.90 & 1.50 & $2.10^{-}$ \\
\hline & 4 & 2.9362 & 6.0712 & & 3 & 0.5196152 & 0.0670820 & & 6.45 & 4 & 5.55 \\
\hline & & 9 & 6.6346 & & & 9 & 1.1618950 & & & 15.50 & 9 \\
\hline & & & 15 & & & & 15 & & & & 27.45 \\
\hline & & $=0.75$ & & & & $\varepsilon=0.75$ & & & & 0.75 & \\
\hline
\end{tabular}

Note. $\mathrm{UN}=$ unstructured model; $\mathrm{ARH}=$ heterogeneous first-order autroregressive model; $\mathrm{RC}=$ random coefficients model; $\varepsilon=$ sphericity index 
Table 2. Group sizes of balanced and unbalanced designs with $J=3, K=4$, 6 and $8, \mathrm{UN}, \mathrm{ARH}$ and RC population covariance matrices, and $\varepsilon=0.57$

\begin{tabular}{ccccccc} 
and $\varepsilon=0.75$ & \multicolumn{7}{c}{} \\
\hline$N$ & $n_{l}$ & $n_{2}$ & $n_{3}$ & $\Delta n_{j}$ & $\begin{array}{c}\text { Covariances } \\
\text { between groups }\end{array}$ & Pairing \\
\hline 30 & 10 & 10 & 10 & 0.00 & $=$ & Null \\
36 & 12 & 12 & 12 & 0.00 & $=$ & Null \\
42 & 14 & 14 & 14 & 0.00 & $\neq$ & Null \\
30 & 10 & 10 & 10 & 0.00 & $\neq$ & Null \\
36 & 12 & 12 & 12 & 0.00 & $\neq$ & Null \\
42 & 14 & 14 & 14 & 0.00 & $\neq$ & + \\
30 & 5 & 10 & 15 & 0.41 & $\neq$ & + \\
36 & 6 & 12 & 18 & 0.41 & $\neq$ & - \\
42 & 7 & 14 & 21 & 0.41 & $\neq$ & - \\
30 & 15 & 10 & 5 & 0.41 & $\neq$ & - \\
36 & 18 & 12 & 6 & 0.41 & $\neq$ & + \\
42 & 21 & 14 & 7 & 0.41 & & + \\
\hline
\end{tabular}

Notes. $J$ : groups, $K$ : number of repeated measurements, $\varepsilon$ : sphericity, $N$ : total sample size, $n_{1}, \quad n_{2}$ and $n_{3}$ : group sizes, $\Delta n_{j}$ : variance coefficient of the group size, $=/ \neq$ : homogeneity/heterogeneity of covariance matrices between groups, null/+/-: null/positive/negative pairing of group sizes and covariance matrices. 
Table 3. Percentages $\theta$ fit of the 11 candidate covariance structures selected by AIC for to the UN population matrix selected by AIC.

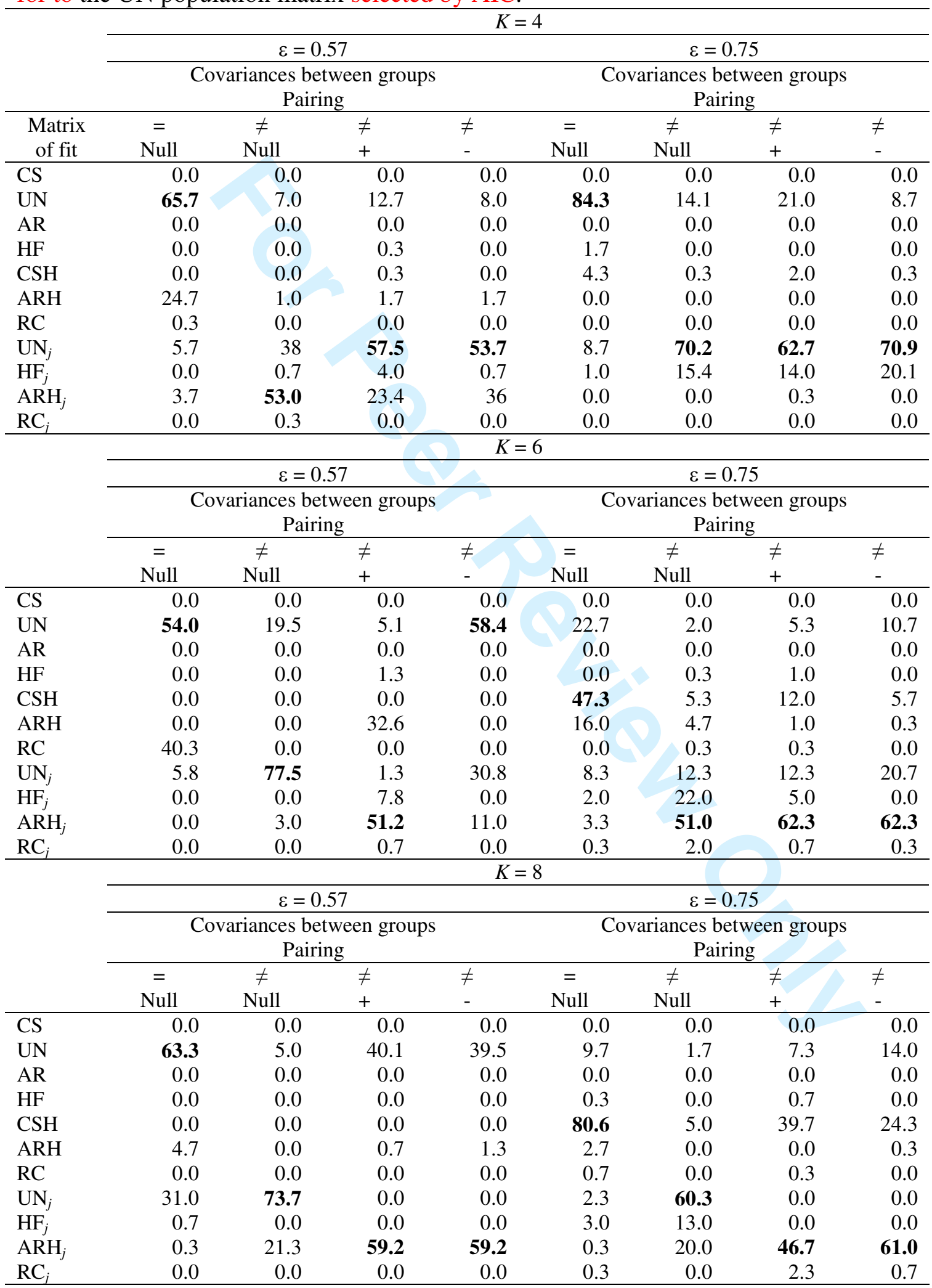

Note. In bold = selected matrix The structure with the highest selection percentage is in bold 
Table 4. Percentages of fit of the 11 candidate covariance structures selected by AIC for to the ARH population matrix selected by AIC.

\begin{tabular}{|c|c|c|c|c|c|c|c|c|}
\hline & \multicolumn{8}{|c|}{$K=4$} \\
\hline & \multicolumn{4}{|c|}{$\varepsilon=0.57$} & \multicolumn{4}{|c|}{$\varepsilon=0.75$} \\
\hline & \multicolumn{4}{|c|}{$\begin{array}{l}\text { Covariances between groups } \\
\text { Pairing }\end{array}$} & \multicolumn{4}{|c|}{$\begin{array}{l}\text { Covariances between groups } \\
\text { Pairing }\end{array}$} \\
\hline Matrix & $=$ & $\neq$ & $\neq$ & $\neq$ & $=$ & $\neq$ & $\neq$ & $\neq$ \\
\hline of fit & Null & Null & + & - & Null & Null & + & - \\
\hline $\mathrm{CS}$ & 0.0 & 0.0 & 0.0 & 0.0 & 0.0 & 0.0 & 0.0 & 0.0 \\
\hline UN & 11.7 & 1.3 & 1.3 & 2.4 & 10.7 & 3.0 & 1.7 & 1.3 \\
\hline $\mathrm{AR}$ & 0.0 & 0.0 & 0.0 & 0.0 & 0.0 & 0.0 & 0.0 & 0.0 \\
\hline $\mathrm{HF}$ & 0.0 & 0.0 & 0.0 & 0.0 & 0.0 & 0.0 & 0.0 & 0.0 \\
\hline $\mathrm{CSH}$ & 0.7 & 0.3 & 0.0 & 0.0 & 34.0 & 2.7 & 3.0 & 2.0 \\
\hline ARH & 78.0 & 4.0 & 4.7 & 3.7 & 46.7 & 1.0 & 3.7 & 1.0 \\
\hline $\mathrm{RC}$ & 0.0 & 0.0 & 0.0 & 0.0 & 0.0 & 0.3 & 0.3 & 0.0 \\
\hline $\mathrm{UN}_{j}$ & 4.3 & 10.7 & 26.7 & 28.7 & 3.7 & 12.0 & 24.0 & 24.3 \\
\hline $\mathrm{HF}_{j}$ & 0.0 & 0.3 & 1.0 & 1.7 & 0.3 & 4.0 & 4.0 & 8.3 \\
\hline $\mathrm{ARH}_{j}$ & 5.3 & 83.3 & 66.3 & 63.5 & 3.3 & 76.3 & 62.7 & 62.3 \\
\hline \multirow[t]{6}{*}{$\mathrm{RC}_{j}$} & 0.0 & 0.0 & 0.0 & 0.0 & 1.3 & 0.7 & 0.7 & 0.7 \\
\hline & \multicolumn{8}{|c|}{$K=6$} \\
\hline & \multicolumn{4}{|c|}{$\varepsilon=0.57$} & \multicolumn{4}{|c|}{$\varepsilon=0.75$} \\
\hline & \multicolumn{4}{|c|}{$\begin{array}{c}\text { Covariances between groups } \\
\text { Pairing }\end{array}$} & \multicolumn{4}{|c|}{$\begin{array}{c}\text { Covariances between groups } \\
\text { Pairing }\end{array}$} \\
\hline & $=$ & $\neq$ & $\neq$ & $\neq$ & $=$ & $\neq$ & $\neq$ & $\neq$ \\
\hline & Null & Null & + & - & Null & Null & + & - \\
\hline CS & 0.0 & 0.0 & 0.0 & 0.0 & 0.0 & 0.0 & 0.0 & 0.0 \\
\hline UN & 3.7 & 0.0 & 0.0 & 0.0 & 3.3 & 0.0 & 0.0 & 2.7 \\
\hline AR & 0.0 & 0.0 & 0.0 & 0.0 & 0.0 & 0.0 & 0.0 & 0.0 \\
\hline $\mathrm{HF}$ & 0.0 & 0.0 & 0.3 & 0.0 & 0.0 & 0.0 & 1.7 & 0.0 \\
\hline $\mathrm{CSH}$ & 0.0 & 0.0 & 1.5 & 0.0 & 8.7 & 0.3 & 9.0 & 0.0 \\
\hline ARH & 88.6 & 0.0 & 21.9 & 1.3 & 79.7 & 1.3 & 20.7 & 1.3 \\
\hline $\mathrm{RC}$ & 1.7 & 0.0 & 0.3 & 0.0 & 0.0 & 0.0 & 3.0 & 0.0 \\
\hline $\mathrm{UN}_{j}$ & 3.3 & 10.3 & 0.7 & 9.0 & 4.7 & 12.0 & 0.7 & 12.7 \\
\hline $\mathrm{HF}_{j}$ & 0.0 & 0.3 & 1.3 & 0.3 & 0.0 & 1.7 & 2.3 & 1.3 \\
\hline $\mathrm{ARH}_{j}$ & 2.7 & 89.3 & 66.4 & 89.0 & 3.3 & 84.7 & 56.5 & 81.7 \\
\hline \multirow[t]{7}{*}{$\mathrm{RC}_{j}$} & 0.0 & 0.0 & 1.3 & 0.0 & 0.3 & 0.0 & 6.0 & 0.3 \\
\hline & \multicolumn{8}{|c|}{$K=8$} \\
\hline & \multicolumn{4}{|c|}{$\varepsilon=0.57$} & \multicolumn{4}{|c|}{$\varepsilon=0.75$} \\
\hline & \multirow{2}{*}{\multicolumn{4}{|c|}{$\begin{array}{c}\text { Covariances between groups } \\
\text { Pairing }\end{array}$}} & \multirow{2}{*}{\multicolumn{4}{|c|}{$\begin{array}{c}\text { Covariances between groups } \\
\text { Pairing }\end{array}$}} \\
\hline & & & & & & & & \\
\hline & $=$ & $\neq$ & $\neq$ & $\neq$ & $=$ & $\neq$ & & $\neq$ \\
\hline & Null & Null & + & - & Null & Null & + & - \\
\hline $\mathrm{CS}$ & 0.0 & 0.0 & 0.0 & 0.0 & 0.0 & 0.0 & 0.0 & 0.0 \\
\hline UN & 1.3 & 0.0 & 0.0 & 0.3 & 40.7 & 7.0 & 88.3 & 79.3 \\
\hline AR & 0.0 & 0.0 & 0.0 & 0.0 & 0.0 & 0.0 & 0.0 & 0.0 \\
\hline $\mathrm{HF}$ & 0.0 & 0.0 & 0.0 & 0.0 & 2.3 & 0.3 & 1.3 & 3.3 \\
\hline $\mathrm{CSH}$ & 0.0 & 0.0 & 0.0 & 0.0 & 18.7 & 2.0 & 6.3 & 9.7 \\
\hline ARH & 79.7 & 0.3 & 2.7 & 4.3 & 0.0 & 0.0 & 0.0 & 0.0 \\
\hline $\mathrm{RC}$ & 0.0 & 0.0 & 0.0 & 0.0 & 4.3 & 0.3 & 0.7 & 1.0 \\
\hline $\mathrm{UN}_{j}$ & 16.7 & 22.0 & 0.0 & 10.7 & 27.7 & 90.0 & 0.0 & 0.0 \\
\hline $\mathrm{HF}_{j}$ & 1.3 & 0.3 & 0.0 & 0.0 & 6.0 & 0.0 & 0.0 & 0.0 \\
\hline $\mathrm{ARH}_{j}$ & 1.0 & 77.3 & 97.3 & 84.7 & 0.0 & 0.0 & 1.0 & 0.3 \\
\hline $\mathrm{RC}_{j}$ & 0.0 & 0.0 & 0.0 & 0.0 & 0.3 & 0.3 & 2.3 & 6.3 \\
\hline
\end{tabular}

Note. In bold = selected matrix The structure with the highest selection percentage is in bold 
Table 5. Percentages $\theta$ f fit of the 11 candidate covariance structures selected by AIC for to the RC population matrix selected by AIC.



Note. In bold = selected matrix The structure with the highest selection percentage is in bold 
Table 6. Empirical rates of Type I error for the time and interaction effects (nominal value 0.05). Simulated covariance structure UN with $K=4,6$ and 8 repeated measures and $\varepsilon=0.57$

\begin{tabular}{|c|c|c|c|c|c|c|c|c|c|c|c|c|c|c|c|}
\hline \multicolumn{16}{|c|}{ Time effect } \\
\hline \multirow[b]{2}{*}{$N$} & \multirow[b]{2}{*}{$n_{1}$} & \multirow[b]{2}{*}{$n_{2}$} & \multirow[b]{2}{*}{$n_{3}$} & \multirow[b]{2}{*}{$\Delta n_{j}$} & \multirow[b]{2}{*}{$\begin{array}{c}\text { Covariances } \\
\text { between } \\
\text { groups }\end{array}$} & \multirow[b]{2}{*}{ Pairing } & \multicolumn{3}{|c|}{$K=4$} & \multicolumn{3}{|c|}{$K=6$} & \multicolumn{3}{|c|}{$K=8$} \\
\hline & & & & & & & $\mathrm{BW}$ & SW & $\mathrm{KR}$ & $\mathrm{BW}$ & SW & $\mathrm{KR}$ & $\mathrm{BW}$ & SW & $\mathrm{KR}$ \\
\hline 30 & 10 & 10 & 10 & 0.00 & $=$ & Null & 0.087 & 0.092 & 0.075 & 0.091 & 0.093 & 0.069 & 0.102 & 0.086 & 0.068 \\
\hline 36 & 12 & 12 & 12 & 0.00 & $=$ & Null & 0.081 & 0.086 & 0.067 & 0.073 & 0.077 & 0.063 & 0.072 & 0.074 & 0.060 \\
\hline 42 & 14 & 14 & 14 & 0.00 & $=$ & Null & 0.070 & 0.071 & 0.061 & 0.082 & 0.082 & 0.072 & 0.079 & 0.079 & 0.068 \\
\hline 30 & 10 & 10 & 10 & 0.00 & $\neq$ & Null & 0.097 & 0.084 & 0.070 & 0.126 & 0.088 & 0.064 & 0.123 & 0.097 & 0.071 \\
\hline 36 & 12 & 12 & 12 & 0.00 & $\neq$ & Null & 0.085 & 0.071 & 0.061 & 0.110 & 0.088 & 0.061 & 0.107 & 0.079 & 0.070 \\
\hline 42 & 14 & 14 & 14 & 0.00 & $\neq$ & Null & 0.088 & 0.072 & 0.060 & 0.091 & 0.067 & 0.058 & 0.095 & 0.075 & 0.064 \\
\hline 30 & 5 & 10 & 15 & 0.41 & $\neq$ & + & 0.117 & 0.089 & 0.063 & 0.097 & 0.083 & 0.073 & 0.090 & 0.080 & 0.064 \\
\hline 36 & 6 & 12 & 18 & 0.41 & $\neq$ & + & 0.113 & 0.089 & 0.073 & 0.090 & 0.075 & 0.059 & 0.063 & 0.057 & 0.049 \\
\hline 42 & 7 & 14 & 21 & 0.41 & $\neq$ & + & 0.093 & 0.082 & 0.067 & 0.083 & 0.078 & 0.071 & 0.077 & 0.067 & 0.060 \\
\hline 30 & 15 & 10 & 5 & 0.41 & $\neq$ & - & 0.231 & 0.150 & 0.109 & 0.268 & 0.272 & 0.243 & 0.158 & 0.107 & 0.077 \\
\hline 36 & 18 & 12 & 6 & 0.41 & $\neq$ & - & 0.192 & 0.127 & 0.082 & 0.224 & 0.228 & 0.206 & 0.118 & 0.076 & 0.054 \\
\hline 42 & 21 & 14 & 7 & 0.41 & $\neq$ & - & 0.189 & 0.133 & 0.098 & 0.182 & 0.132 & 0.105 & 0.129 & 0.101 & 0.072 \\
\hline \multicolumn{16}{|c|}{ Interaction effect } \\
\hline & & & & & & & & $K=4$ & & & $K=6$ & & & $K=8$ & \\
\hline$N$ & $n_{1}$ & $n_{2}$ & $n_{3}$ & $\Delta n_{j}$ & $\begin{array}{c}\text { Covariances } \\
\text { between } \\
\text { groups }\end{array}$ & Pairing & BW & SW & KR & BW & SW & KR & $\mathrm{BW}$ & SW & KR \\
\hline 30 & 10 & 10 & 10 & 0.00 & $=$ & Null & 0.083 & 0.089 & 0.071 & 0.097 & 0.101 & 0.084 & 0.211 & 0.144 & 0.076 \\
\hline 36 & 12 & 12 & 12 & 0.00 & $=$ & Null & 0.080 & 0.083 & 0.066 & 0.067 & 0.071 & 0.059 & 0.074 & 0.077 & 0.062 \\
\hline 42 & 14 & 14 & 14 & 0.00 & $=$ & Null & 0.079 & 0.081 & 0.067 & 0.090 & 0.093 & 0.075 & 0.065 & 0.068 & 0.060 \\
\hline 30 & 10 & 10 & 10 & 0.00 & $\neq$ & Null & 0.139 & 0.096 & 0.068 & 0.228 & 0.151 & 0.066 & 0.218 & 0.144 & 0.074 \\
\hline 36 & 12 & 12 & 12 & 0.00 & $\neq$ & Null & 0.134 & 0.099 & 0.075 & 0.193 & 0.126 & 0.069 & 0.197 & 0.128 & 0.071 \\
\hline 42 & 14 & 14 & 14 & 0.00 & $\neq$ & Null & 0.093 & 0.069 & 0.047 & 0.162 & 0.105 & 0.060 & 0.176 & 0.123 & 0.075 \\
\hline 30 & 5 & 10 & 15 & 0.41 & $\neq$ & + & 0.236 & 0.162 & 0.074 & 0.135 & 0.098 & 0.062 & 0.144 & 0.101 & 0.066 \\
\hline 36 & 6 & 12 & 18 & 0.41 & $\neq$ & + & 0.197 & 0.129 & 0.059 & 0.127 & 0.099 & 0.070 & 0.105 & 0.083 & 0.053 \\
\hline 42 & 7 & 14 & 21 & 0.41 & $\neq$ & + & 0.153 & 0.113 & 0.070 & 0.130 & 0.101 & 0.071 & 0.122 & 0.087 & 0.070 \\
\hline 30 & 15 & 10 & 5 & 0.41 & $\neq$ & - & 0.429 & 0.276 & 0.153 & 0.294 & 0.301 & 0.272 & 0.238 & 0.139 & 0.087 \\
\hline 36 & 18 & 12 & 6 & 0.41 & $\neq$ & - & 0.348 & 0.229 & 0.131 & 0.265 & 0.267 & 0.233 & 0.186 & 0.131 & 0.073 \\
\hline 42 & 21 & 14 & 7 & 0.41 & $\neq$ & - & 0.303 & 0.202 & 0.126 & 0.297 & 0.198 & 0.120 & 0.175 & 0.116 & 0.074 \\
\hline
\end{tabular}

Note. BW, SW and KR = methods for calculating the degrees of freedom (Between-Within, Satterthwaite and KenwardRoger) In bold = liberal 
Table 7. Empirical rates of Type I error for the time and interaction effects (nominal value 0.05). Simulated covariance structure ARH with $K=4,6$ and 8 repeated measures and $\varepsilon=0.57$

\begin{tabular}{|c|c|c|c|c|c|c|c|c|c|c|c|c|c|c|c|}
\hline \multicolumn{16}{|c|}{ Time effect } \\
\hline \multirow[b]{2}{*}{$N$} & \multirow[b]{2}{*}{$n_{1}$} & \multirow[b]{2}{*}{$n_{2}$} & \multirow[b]{2}{*}{$n_{3}$} & \multirow[b]{2}{*}{$\Delta n_{j}$} & \multirow[b]{2}{*}{$\begin{array}{c}\text { Covariances } \\
\text { between } \\
\text { groups }\end{array}$} & \multirow[b]{2}{*}{ Pairing } & \multicolumn{3}{|c|}{$K=4$} & \multicolumn{3}{|c|}{$K=6$} & \multicolumn{3}{|c|}{$K=8$} \\
\hline & & & & & & & $\mathrm{BW}$ & SW & $\mathrm{KR}$ & $\mathrm{BW}$ & SW & $\mathrm{KR}$ & $\mathrm{BW}$ & SW & $\mathrm{KR}$ \\
\hline 30 & 10 & 10 & 10 & 0.00 & $=$ & Null & 0.096 & 0.083 & 0.073 & 0.095 & 0.079 & 0.070 & 0.088 & 0.078 & 0.073 \\
\hline 36 & 12 & 12 & 12 & 0.00 & $=$ & Null & 0.081 & 0.071 & 0.064 & 0.083 & 0.067 & 0.065 & 0.073 & 0.064 & 0.063 \\
\hline 42 & 14 & 14 & 14 & 0.00 & $=$ & Null & 0.065 & 0.056 & 0.054 & 0.083 & 0.072 & 0.068 & 0.066 & 0.062 & 0.062 \\
\hline 30 & 10 & 10 & 10 & 0.00 & $\neq$ & Null & 0.094 & 0.074 & 0.064 & 0.096 & 0.074 & 0.061 & 0.112 & 0.084 & 0.065 \\
\hline 36 & 12 & 12 & 12 & 0.00 & $\neq$ & Null & 0.080 & 0.062 & 0.051 & 0.065 & 0.055 & 0.046 & 0.079 & 0.067 & 0.064 \\
\hline 42 & 14 & 14 & 14 & 0.00 & $\neq$ & Null & 0.093 & 0.079 & 0.071 & 0.070 & 0.063 & 0.053 & 0.076 & 0.067 & 0.064 \\
\hline 30 & 5 & 10 & 15 & 0.41 & $\neq$ & + & 0.095 & 0.082 & 0.065 & 0.094 & 0.078 & 0.066 & 0.092 & 0.074 & 0.065 \\
\hline 36 & 6 & 12 & 18 & 0.41 & $\neq$ & + & 0.068 & 0.054 & 0.047 & 0.093 & 0.078 & 0.071 & 0.079 & 0.068 & 0.064 \\
\hline 42 & 7 & 14 & 21 & 0.41 & $\neq$ & + & 0.069 & 0.058 & 0.054 & 0.068 & 0.057 & 0.052 & 0.077 & 0.065 & 0.065 \\
\hline 30 & 15 & 10 & 5 & 0.41 & $\neq$ & - & 0.174 & 0.112 & 0.092 & 0.149 & 0.091 & 0.065 & 0.147 & 0.096 & 0.082 \\
\hline 36 & 18 & 12 & 6 & 0.41 & $\neq$ & - & 0.158 & 0.108 & 0.083 & 0.133 & 0.087 & 0.074 & 0.140 & 0.088 & 0.075 \\
\hline 42 & 21 & 14 & 7 & 0.41 & $\neq$ & - & 0.116 & 0.069 & 0.052 & 0.108 & 0.075 & 0.060 & 0.124 & 0.086 & 0.071 \\
\hline \multicolumn{16}{|c|}{ Interaction effect } \\
\hline & & & & & & & & $K=4$ & & & $K=6$ & & & $K=8$ & \\
\hline$N$ & $n_{1}$ & $n_{2}$ & $n_{3}$ & $\Delta n_{j}$ & $\begin{array}{c}\text { Covariances } \\
\text { between } \\
\text { groups }\end{array}$ & Pairing & BW & SW & KR & BW & SW & KR & $\mathrm{BW}$ & SW & KR \\
\hline 30 & 10 & 10 & 10 & 0.00 & $=$ & Null & 0.098 & 0.081 & 0.078 & 0.093 & 0.076 & 0.072 & 0.089 & 0.069 & 0.070 \\
\hline 36 & 12 & 12 & 12 & 0.00 & $=$ & Null & 0.080 & 0.066 & 0.062 & 0.090 & 0.067 & 0.067 & 0.074 & 0.055 & 0.055 \\
\hline 42 & 14 & 14 & 14 & 0.00 & $=$ & Null & 0.075 & 0.066 & 0.064 & 0.084 & 0.076 & 0.074 & 0.085 & 0.070 & 0.069 \\
\hline 30 & 10 & 10 & 10 & 0.00 & $\neq$ & Null & 0.139 & 0.089 & 0.065 & 0.136 & 0.087 & 0.057 & 0.228 & 0.155 & 0.079 \\
\hline 36 & 12 & 12 & 12 & 0.00 & $\neq$ & Null & 0.113 & 0.080 & 0.062 & 0.121 & 0.082 & 0.058 & 0.126 & 0.091 & 0.073 \\
\hline 42 & 14 & 14 & 14 & 0.00 & $\neq$ & Null & 0.111 & 0.085 & 0.074 & 0.112 & 0.077 & 0.055 & 0.112 & 0.078 & 0.067 \\
\hline 30 & 5 & 10 & 15 & 0.41 & $\neq$ & + & 0.146 & 0.101 & 0.054 & 0.135 & 0.100 & 0.065 & 0.148 & 0.096 & 0.077 \\
\hline 36 & 6 & 12 & 18 & 0.41 & $\neq$ & + & 0.126 & 0.084 & 0.056 & 0.135 & 0.088 & 0.053 & 0.110 & 0.075 & 0.058 \\
\hline 42 & 7 & 14 & 21 & 0.41 & $\neq$ & + & 0.107 & 0.078 & 0.061 & 0.095 & 0.071 & 0.052 & 0.102 & 0.073 & 0.061 \\
\hline 30 & 15 & 10 & 5 & 0.41 & $\neq$ & - & 0.261 & 0.141 & 0.099 & 0.225 & 0.122 & 0.072 & 0.238 & 0.129 & 0.091 \\
\hline 36 & 18 & 12 & 6 & 0.41 & $\neq$ & - & 0.208 & 0.129 & 0.094 & 0.189 & 0.109 & 0.072 & 0.187 & 0.124 & 0.095 \\
\hline 42 & 21 & 14 & 7 & 0.41 & $\neq$ & - & 0.158 & 0.085 & 0.056 & 0.163 & 0.097 & 0.071 & 0.157 & 0.089 & 0.071 \\
\hline
\end{tabular}

Note. BW, SW and KR = methods for calculating the degrees of freedom (Between-Within, Satterthwaite and KenwardRoger) In bold = liberal 
Table 8. Empirical rates of Type I error for the time and interaction effects (nominal value 0.05). Simulated covariance structure RC with $K=4,6$ and 8 repeated measures and $\varepsilon=0.57$

\begin{tabular}{|c|c|c|c|c|c|c|c|c|c|c|c|c|c|c|c|}
\hline \multicolumn{16}{|c|}{ Time effect } \\
\hline \multirow[b]{2}{*}{$N$} & \multirow[b]{2}{*}{$n_{1}$} & \multirow[b]{2}{*}{$n_{2}$} & \multirow[b]{2}{*}{$n_{3}$} & \multirow[b]{2}{*}{$\Delta n_{j}$} & \multirow[b]{2}{*}{$\begin{array}{c}\text { Covariances } \\
\text { between } \\
\text { groups }\end{array}$} & \multirow[b]{2}{*}{ Pairing } & \multicolumn{3}{|c|}{$K=4$} & \multicolumn{3}{|c|}{$K=6$} & \multicolumn{3}{|c|}{$K=8$} \\
\hline & & & & & & & $\mathrm{BW}$ & SW & $\mathrm{KR}$ & $\mathrm{BW}$ & SW & $\mathrm{KR}$ & $\mathrm{BW}$ & SW & $\mathrm{KR}$ \\
\hline 30 & 10 & 10 & 10 & 0.00 & $=$ & Null & 0.066 & 0.053 & 0.051 & 0.079 & 0.065 & 0.064 & 0.099 & 0.084 & 0.071 \\
\hline 36 & 12 & 12 & 12 & 0.00 & $=$ & Null & 0.063 & 0.053 & 0.049 & 0.075 & 0.067 & 0.064 & 0.071 & 0.063 & 0.061 \\
\hline 42 & 14 & 14 & 14 & 0.00 & $=$ & Null & 0.063 & 0.067 & 0.059 & 0.078 & 0.071 & 0.067 & 0.072 & 0.067 & 0.066 \\
\hline 30 & 10 & 10 & 10 & 0.00 & $\neq$ & Null & 0.105 & 0.092 & 0.076 & 0.129 & 0.100 & 0.076 & 0.131 & 0.098 & 0.075 \\
\hline 36 & 12 & 12 & 12 & 0.00 & $\neq$ & Null & 0.101 & 0.082 & 0.063 & 0.108 & 0.086 & 0.074 & 0.119 & 0.100 & 0.078 \\
\hline 42 & 14 & 14 & 14 & 0.00 & $\neq$ & Null & 0.087 & 0.072 & 0.064 & 0.075 & 0.059 & 0.050 & 0.097 & 0.086 & 0.069 \\
\hline 30 & 5 & 10 & 15 & 0.41 & $\neq$ & + & 0.105 & 0.085 & 0.071 & 0.108 & 0.083 & 0.095 & 0.017 & 0.015 & 0.015 \\
\hline 36 & 6 & 12 & 18 & 0.41 & $\neq$ & + & 0.089 & 0.069 & 0.056 & 0.068 & 0.046 & 0.064 & 0.013 & 0.013 & 0.013 \\
\hline 42 & 7 & 14 & 21 & 0.41 & $\neq$ & + & 0.089 & 0.082 & 0.068 & 0.001 & 0.001 & 0.001 & 0.015 & 0.015 & 0.015 \\
\hline 30 & 15 & 10 & 5 & 0.41 & $\neq$ & - & 0.226 & 0.141 & 0.103 & 0.127 & 0.095 & 0.069 & 0.274 & 0.276 & 0.249 \\
\hline 36 & 18 & 12 & 6 & 0.41 & $\neq$ & - & 0.208 & 0.136 & 0.090 & 0.223 & 0.205 & 0.202 & 0.111 & 0.077 & 0.065 \\
\hline 42 & 21 & 14 & 7 & 0.41 & $\neq$ & - & 0.169 & 0.118 & 0.085 & 0.177 & 0.126 & 0.088 & 0.114 & 0.080 & 0.067 \\
\hline \multicolumn{16}{|c|}{ Interaction effect } \\
\hline & & & & & & & & $K=4$ & & & $K=6$ & & & $K=8$ & \\
\hline$N$ & $n_{1}$ & $n_{2}$ & $n_{3}$ & $\Delta n_{j}$ & $\begin{array}{c}\text { Covariances } \\
\text { between } \\
\text { groups }\end{array}$ & Pairing & BW & SW & KR & BW & SW & KR & BW & SW & KR \\
\hline 30 & 10 & 10 & 10 & 0.00 & $=$ & Null & 0.066 & 0.056 & 0.055 & 0.097 & 0.079 & 0.075 & 0.194 & 0.133 & 0.056 \\
\hline 36 & 12 & 12 & 12 & 0.00 & $=$ & Null & 0.055 & 0.043 & 0.041 & 0.081 & 0.064 & 0.064 & 0.091 & 0.077 & 0.078 \\
\hline 42 & 14 & 14 & 14 & 0.00 & $=$ & Null & 0.072 & 0.072 & 0.061 & 0.075 & 0.060 & 0.059 & 0.080 & 0.065 & 0.066 \\
\hline 30 & 10 & 10 & 10 & 0.00 & $\neq$ & Null & 0.155 & 0.106 & 0.084 & 0.227 & 0.162 & 0.091 & 0.204 & 0.143 & 0.076 \\
\hline 36 & 12 & 12 & 12 & 0.00 & $\neq$ & Null & 0.211 & 0.131 & 0.073 & 0.187 & 0.125 & 0.078 & 0.190 & 0.129 & 0.069 \\
\hline 42 & 14 & 14 & 14 & 0.00 & $\neq$ & Null & 0.127 & 0.092 & 0.079 & 0.149 & 0.103 & 0.059 & 0.156 & 0.104 & 0.068 \\
\hline 30 & 5 & 10 & 15 & 0.41 & $\neq$ & + & 0.254 & 0.172 & 0.087 & 0.244 & 0.185 & 0.012 & 0.027 & 0.020 & 0.021 \\
\hline 36 & 6 & 12 & 18 & 0.41 & $\neq$ & + & 0.193 & 0.143 & 0.072 & 0.251 & 0.069 & 0.098 & 0.023 & 0.015 & 0.015 \\
\hline 42 & 7 & 14 & 21 & 0.41 & $\neq$ & + & 0.156 & 0.105 & 0.071 & 0.031 & 0.025 & 0.024 & 0.028 & 0.023 & 0.023 \\
\hline 30 & 15 & 10 & 5 & 0.41 & $\neq$ & - & 0.425 & 0.287 & 0.178 & 0.222 & 0.118 & 0.082 & 0.291 & 0.295 & 0.273 \\
\hline 36 & 18 & 12 & 6 & 0.41 & $\neq$ & - & 0.337 & 0.225 & 0.125 & 0.246 & 0.229 & 0.224 & 0.177 & 0.083 & 0.072 \\
\hline 42 & 21 & 14 & 7 & 0.41 & $\neq$ & - & 0.271 & 0.173 & 0.112 & 0.306 & 0.200 & 0.121 & 0.150 & 0.082 & 0.071 \\
\hline
\end{tabular}

Note. BW, SW and KR = methods for calculating the degrees of freedom (Between-Within, Satterthwaite and KenwardRoger) In bold = liberal; in italics = conservative 
Table 9. Empirical rates of Type I error for the time and interaction effects (nominal value 0.05). Simulated covariance structure UN with $K=4,6$ and 8 repeated measures $\varepsilon=0.75$

\begin{tabular}{|c|c|c|c|c|c|c|c|c|c|c|c|c|c|c|c|}
\hline \multicolumn{16}{|c|}{ Time effect } \\
\hline \multirow[b]{2}{*}{$N$} & \multirow[b]{2}{*}{$n_{1}$} & \multirow[b]{2}{*}{$n_{2}$} & \multirow[b]{2}{*}{$n_{3}$} & \multirow[b]{2}{*}{$\Delta n_{j}$} & \multirow[b]{2}{*}{$\begin{array}{c}\text { Covariances } \\
\text { between } \\
\text { groups }\end{array}$} & \multirow[b]{2}{*}{ Pairing } & \multicolumn{3}{|c|}{$K=4$} & \multicolumn{3}{|c|}{$K=6$} & \multicolumn{3}{|c|}{$K=8$} \\
\hline & & & & & & & BW & SW & KR & BW & SW & KR & BW & SW & KR \\
\hline 30 & 10 & 10 & 10 & 0.00 & $=$ & Null & 0.079 & 0.081 & 0.067 & 0.096 & 0.082 & 0.079 & 0.089 & 0.072 & 0.070 \\
\hline 36 & 12 & 12 & 12 & 0.00 & $=$ & Null & 0.082 & 0.083 & 0.073 & 0.076 & 0.066 & 0.063 & 0.077 & 0.070 & 0.067 \\
\hline 42 & 14 & 14 & 14 & 0.00 & $=$ & Null & 0.070 & 0.073 & 0.057 & 0.055 & 0.050 & 0.049 & 0.067 & 0.057 & 0.056 \\
\hline 30 & 10 & 10 & 10 & 0.00 & $\neq$ & Null & 0.107 & 0.083 & 0.070 & 0.090 & 0.076 & 0.063 & 0.103 & 0.071 & 0.053 \\
\hline 36 & 12 & 12 & 12 & 0.00 & $\neq$ & Null & 0.112 & 0.089 & 0.075 & 0.056 & 0.048 & 0.045 & 0.104 & 0.080 & 0.059 \\
\hline 42 & 14 & 14 & 14 & 0.00 & $\neq$ & Null & 0.070 & 0.055 & 0.048 & 0.078 & 0.068 & 0.064 & 0.095 & 0.077 & 0.061 \\
\hline 30 & 5 & 10 & 15 & 0.41 & $\neq$ & + & 0.109 & 0.079 & 0.067 & 0.076 & 0.064 & 0.055 & 0.077 & 0.064 & 0.059 \\
\hline 36 & 6 & 12 & 18 & 0.41 & $\neq$ & + & 0.107 & 0.090 & 0.073 & 0.065 & 0.059 & 0.052 & 0.080 & 0.072 & 0.065 \\
\hline 42 & 7 & 14 & 21 & 0.41 & $\neq$ & + & 0.098 & 0.084 & 0.064 & 0.061 & 0.054 & 0.046 & 0.084 & 0.075 & 0.071 \\
\hline 30 & 15 & 10 & 5 & 0.4 & $\neq$ & - & 239 & 0.165 & 0.133 & .156 & 0.110 & 92 & & 0.105 & 0.083 \\
\hline 36 & 18 & 12 & 6 & 0.41 & $\neq$ & - & 0.237 & 0.150 & 0.107 & 0.140 & 0.090 & 0.068 & 0.139 & 0.096 & 0.080 \\
\hline 42 & 21 & 14 & 7 & 0.41 & $\neq$ & - & 0.186 & 0.129 & 0.098 & 0.116 & 0.077 & 0.064 & 0.104 & 0.076 & 0.065 \\
\hline \multicolumn{16}{|c|}{ tion effect } \\
\hline & & & & & & & & $K=4$ & & & $K=6$ & & & $K=8$ & \\
\hline$N$ & $n_{1}$ & $n_{2}$ & $n_{3}$ & $\Delta n_{j}$ & $\begin{array}{c}\text { Covariances } \\
\text { between } \\
\text { groups }\end{array}$ & Pairing & BW & SW & KR & BW & SW & KR & BW & SW & KR \\
\hline 30 & 10 & 10 & 10 & 0.00 & $=$ & Null & 0.097 & 0.102 & 0.080 & 0.106 & 0.091 & 0.091 & 0.087 & 0.072 & 0.069 \\
\hline 36 & 12 & 12 & 12 & & $=$ & Null & 0.079 & 0.0 & 0.067 & 0.080 & 0.068 & & & 0.0 & 0.072 \\
\hline 42 & 14 & 14 & 14 & 0.00 & $=$ & Null & 0.084 & 0.089 & 0.071 & 0.077 & 0.069 & 0.065 & 0.081 & 0.073 & 0.073 \\
\hline 30 & 10 & 10 & 10 & 0.00 & $\neq$ & Null & 0.223 & 0.150 & 0.074 & 0.143 & 0.094 & 0.065 & 0.193 & 0.129 & 0.071 \\
\hline 36 & 12 & 12 & 12 & 0.00 & $\neq$ & Null & 0.180 & 0.121 & 0.064 & 0.099 & 0.068 & 0.053 & 0.087 & 0.123 & 0.073 \\
\hline 42 & 14 & 14 & 14 & 0.00 & $\neq$ & Null & 0.168 & 0.123 & 0.069 & 0.106 & 0.085 & 0.072 & 0.163 & 0.116 & 0.071 \\
\hline 30 & 5 & 10 & 15 & & $\neq$ & + & 0.230 & 0.160 & 0.090 & 0.1 & 0.088 & 0.064 & 0.124 & 0.086 & 0.064 \\
\hline 36 & 6 & 12 & 18 & 0.41 & $\neq$ & + & 0.208 & 0.163 & 0.080 & 0.126 & 0.097 & 0.072 & 0.114 & 0.091 & 0.071 \\
\hline 42 & 7 & 14 & 21 & 0.4 & $\neq$ & + & 0.155 & 0.115 & 0.071 & 0.094 & 0.070 & 0.057 & 0.095 & 0.072 & 0.054 \\
\hline 30 & 15 & 10 & 5 & 0. & $\neq$ & - & 0.435 & 0.300 & 0.195 & 0.198 & 0.109 & 0.088 & 0.225 & 0.126 & 0.096 \\
\hline 36 & 18 & 12 & 6 & 0.4 & $\neq$ & - & 0.379 & 0.253 & 0.147 & 0.198 & 0.126 & 0.088 & 0.199 & 0.103 & 0.081 \\
\hline 42 & 21 & 14 & 7 & 0.41 & $\neq$ & - & 0.288 & 0.188 & 0.124 & 0.145 & 0.087 & 0.077 & 0.150 & 0.097 & 0.076 \\
\hline
\end{tabular}

Note. BW, SW and KR = methods for calculating the degrees of freedom (Between-Within, Satterthwaite and KenwardRoger) In bold $=$ liberal 
Table 10. Empirical rates of Type I error for the time and interaction effects (nominal value 0.05). Simulated covariance structure ARH with $K=4,6$ and 8 repeated measures and $\varepsilon=0.75$

\begin{tabular}{|c|c|c|c|c|c|c|c|c|c|c|c|c|c|c|c|}
\hline \multirow[b]{3}{*}{$N$} & \multirow[b]{3}{*}{$n_{1}$} & \multirow[b]{3}{*}{$n_{2}$} & \multirow[b]{3}{*}{$n_{3}$} & \multirow[b]{3}{*}{$\Delta n_{j}$} & \multirow[b]{3}{*}{$\begin{array}{c}\text { Covariances } \\
\text { between } \\
\text { groups }\end{array}$} & \multirow[b]{3}{*}{ Pairing } & \multicolumn{3}{|c|}{ Time effect } & \multirow{2}{*}{\multicolumn{3}{|c|}{$K=6$}} & \multirow{2}{*}{\multicolumn{3}{|c|}{$K=8$}} \\
\hline & & & & & & & \multicolumn{3}{|c|}{$K=4$} & & & & & & \\
\hline & & & & & & & $\mathrm{BW}$ & SW & KR & BW & SW & KR & BW & SW & KR \\
\hline 30 & 10 & 10 & 10 & 0.00 & $=$ & Null & 0.072 & 0.065 & 0.063 & 0.081 & 0.075 & 0.075 & 0.106 & 0.087 & 0.069 \\
\hline 36 & 12 & 12 & 12 & 0.00 & $=$ & Null & 0.075 & 0.065 & 0.062 & 0.104 & 0.093 & 0.092 & 0.081 & 0.084 & 0.069 \\
\hline 42 & 14 & 14 & 14 & 0.00 & $=$ & Null & 0.084 & 0.075 & 0.072 & 0.064 & 0.055 & 0.056 & 0.076 & 0.076 & 0.066 \\
\hline 30 & 10 & 10 & 10 & 0.00 & $\neq$ & Null & 0.074 & 0.055 & 0.053 & 0.095 & 0.080 & 0.075 & 0.120 & 0.087 & 0.067 \\
\hline 36 & 12 & 12 & 12 & 0.00 & $\neq$ & Null & 0.073 & 0.056 & 0.051 & 0.089 & 0.073 & 0.069 & 0.108 & 0.087 & 0.073 \\
\hline 42 & 14 & 14 & 14 & 0.00 & $\neq$ & Null & 0.077 & 0.066 & 0.065 & 0.072 & 0.062 & 0.058 & 0.095 & 0.076 & 0.063 \\
\hline 30 & 5 & 10 & 15 & 0.41 & $\neq$ & + & 0.087 & 0.071 & 0.068 & 0.069 & 0.060 & 0.058 & 0.025 & 0.027 & 0.021 \\
\hline 36 & 6 & 12 & 18 & 0.4 & $\neq$ & + & .068 & 0.053 & 0.054 & 0.091 & 0.076 & 0.075 & 0.014 & 0.014 & 0.010 \\
\hline 42 & 7 & 14 & 21 & 0.41 & $\neq$ & + & 0.068 & 0.053 & 0.072 & 0.069 & 0.059 & 0.061 & 0.015 & 0.015 & 0.014 \\
\hline 30 & 15 & 10 & 5 & 0.4 & $\neq$ & - & 0.197 & 0.122 & 0.098 & 0.169 & 0.107 & 0.094 & 0.284 & 0.285 & 0.254 \\
\hline 36 & 18 & 12 & 6 & 0.4 & $\neq$ & - & 0.134 & 0.099 & 0.086 & 0.100 & 0.062 & 0.053 & 0.254 & 0.258 & 0.230 \\
\hline 42 & 21 & 14 & 7 & 0.41 & $\neq$ & - & 0.126 & 0.088 & 0.082 & 0.123 & 0.092 & 0.074 & 0.243 & 0.248 & 0.225 \\
\hline \multicolumn{16}{|c|}{ Interaction effect } \\
\hline & & & & & & & & $K=4$ & & & $K=6$ & & & $K=8$ & \\
\hline$N$ & $n_{l}$ & $n_{2}$ & $n_{3}$ & $\Delta n_{j}$ & $\begin{array}{c}\text { Covariances } \\
\text { between } \\
\text { groups }\end{array}$ & Pairing & BW & $\mathrm{SW}$ & KR & BW & SW & KR & BW & SW & KR \\
\hline 30 & 10 & 10 & 10 & 0.00 & $=$ & Null & 0.088 & 0.076 & 0.076 & 0.092 & 0.071 & 0.072 & 0.191 & 0.125 & 0.066 \\
\hline 36 & 12 & 12 & 12 & & $=$ & & 0.071 & 0.058 & 0.058 & 0.080 & 0.066 & 0.068 & 0.084 & 0.089 & 0.075 \\
\hline 42 & 14 & 14 & 14 & 0.0 & $=$ & Null & 0.072 & 0.058 & 0.057 & 0.069 & 0.064 & 0.064 & 0.073 & 0.074 & 0.066 \\
\hline 30 & 10 & 10 & 10 & 0.00 & $\neq$ & Null & 0.122 & 0.078 & 0.058 & 0.111 & 0.078 & 0.069 & 0.218 & 0.136 & 0.071 \\
\hline 36 & 12 & 12 & 12 & 0.00 & $\neq$ & Null & 0.102 & 0.068 & 0.056 & 0.105 & 0.067 & 0.054 & 0.178 & 0.119 & 0.064 \\
\hline 42 & 14 & 14 & 14 & 0.00 & $\neq$ & Null & 0.104 & 0.074 & 0.060 & 0.098 & 0.070 & 0.058 & 0.167 & 0.118 & 0.073 \\
\hline 30 & 5 & 10 & 15 & & $\neq$ & + & 119 & 0.089 & 0.072 & 0.1 & 0.0 & 0.058 & 0.040 & 0.044 & 0.036 \\
\hline 36 & 6 & 12 & 18 & 0.41 & $\neq$ & + & .117 & 0.085 & 0.061 & 0.122 & 0.090 & 0.075 & 0.032 & 0.033 & 0.028 \\
\hline 42 & 7 & 14 & 21 & 0.4 & $\neq$ & + & 0.117 & 0.085 & 0.056 & 0.109 & 0.079 & 0.071 & 0.024 & 0.024 & 0.020 \\
\hline 30 & 15 & 10 & 5 & 0. & $\neq$ & - & 0.244 & 0.1 & 0.116 & 0.222 & 0.129 & 0.101 & 0.285 & 0.289 & 0.257 \\
\hline 36 & 18 & 12 & 6 & 0. & $\neq$ & - & 0.177 & 0.099 & 0.079 & 0.169 & 0.094 & 0.078 & 0.292 & 0.299 & 0.272 \\
\hline 42 & 21 & 14 & 7 & 0.41 & $\neq$ & - & 0.166 & 0.110 & 0.093 & 0.143 & 0.078 & 0.070 & 0.255 & 0.259 & 0.244 \\
\hline
\end{tabular}

Note. BW, SW and KR = methods for calculating the degrees of freedom (Between-Within, Satterthwaite and KenwardRoger) In bold = liberal; in italics = conservative 
Table 11. Empirical rates of Type I error for the time and interaction effects (nominal value 0.05). Simulated covariance structure RC with $K=4,6$ and 8 repeated measures and $\varepsilon=0.75$

\begin{tabular}{|c|c|c|c|c|c|c|c|c|c|c|c|c|c|c|c|}
\hline \multicolumn{16}{|c|}{ Time effect } \\
\hline \multirow[b]{2}{*}{$N$} & \multirow[b]{2}{*}{$n_{1}$} & \multirow[b]{2}{*}{$n_{2}$} & \multirow[b]{2}{*}{$n_{3}$} & \multirow[b]{2}{*}{$\Delta n_{j}$} & \multirow[b]{2}{*}{$\begin{array}{c}\text { Covariances } \\
\text { between } \\
\text { groups }\end{array}$} & \multirow[b]{2}{*}{ Pairing } & \multicolumn{3}{|c|}{$K=4$} & \multicolumn{3}{|c|}{$K=6$} & \multicolumn{3}{|c|}{$\mathrm{K}=8$} \\
\hline & & & & & & & $\mathrm{BW}$ & SW & $\mathrm{KR}$ & $\mathrm{BW}$ & SW & $\mathrm{KR}$ & BW & SW & $\mathrm{KR}$ \\
\hline 30 & 10 & 10 & 10 & 0.00 & $=$ & Null & 0.079 & 0.072 & 0.071 & 0.095 & 0.088 & 0.084 & 0.105 & 0.080 & 0.068 \\
\hline 36 & 12 & 12 & 12 & 0.00 & $=$ & Null & 0.071 & 0.058 & 0.058 & 0.083 & 0.069 & 0.065 & 0.066 & 0.068 & 0.060 \\
\hline 42 & 14 & 14 & 14 & 0.00 & $=$ & Null & 0.083 & 0.077 & 0.076 & 0.074 & 0.066 & 0.064 & 0.073 & 0.073 & 0.065 \\
\hline 30 & 10 & 10 & 10 & 0.00 & $\neq$ & Null & 0.092 & 0.070 & 0.069 & 0.115 & 0.087 & 0.066 & 0.119 & 0.081 & 0.066 \\
\hline 36 & 12 & 12 & 12 & 0.00 & $\neq$ & Null & 0.076 & 0.060 & 0.057 & 0.084 & 0.071 & 0.054 & 0.114 & 0.092 & 0.070 \\
\hline 42 & 14 & 14 & 14 & 0.00 & $\neq$ & Null & 0.055 & 0.046 & 0.046 & 0.093 & 0.074 & 0.061 & 0.098 & 0.081 & 0.069 \\
\hline 30 & 5 & 10 & 15 & 0.41 & $\neq$ & + & 0.105 & 0.084 & 0.062 & 0.096 & 0.097 & 0.097 & 0.023 & 0.023 & 0.018 \\
\hline 36 & 6 & 12 & 18 & 0.41 & $\neq$ & + & 0.070 & 0.063 & 0.061 & 0.011 & 0.001 & 0.001 & 0.019 & 0.020 & 0.017 \\
\hline 42 & 7 & 14 & 21 & 0.41 & $\neq$ & + & 0.061 & 0.051 & 0.050 & 0.001 & 0.001 & 0.001 & 0.017 & 0.017 & 0.015 \\
\hline 30 & 15 & 10 & 5 & 0.41 & $\neq$ & - & 0.241 & 0.152 & 0.094 & 0.140 & 0.990 & 0.083 & 0.255 & 0.240 & 0.236 \\
\hline 36 & 18 & 12 & 6 & 0.41 & $\neq$ & - & 0.141 & 0.098 & 0.088 & 0.144 & 0.092 & 0.079 & 0.270 & 0.273 & 0.245 \\
\hline 42 & 21 & 14 & 7 & 0.41 & $\neq$ & - & 0.131 & 0.089 & 0.078 & 0.158 & 0.114 & 0.083 & 0.230 & 0.235 & 0.211 \\
\hline \multicolumn{16}{|c|}{ Interaction effect } \\
\hline & & & & & & & & $K=4$ & & & $K=6$ & & & $K=8$ & \\
\hline$N$ & $n_{1}$ & $n_{2}$ & $n_{3}$ & $\Delta n_{j}$ & $\begin{array}{c}\text { Covariances } \\
\text { between } \\
\text { groups }\end{array}$ & Pairing & BW & SW & KR & BW & SW & KR & BW & SW & KR \\
\hline 30 & 10 & 10 & 10 & 0.00 & $=$ & Null & 0.097 & 0.076 & 0.079 & 0.090 & 0.076 & 0.075 & 0.198 & 0.129 & 0.063 \\
\hline 36 & 12 & 12 & 12 & 0.00 & $=$ & Null & 0.100 & 0.074 & 0.075 & 0.096 & 0.087 & 0.085 & 0.083 & 0.086 & 0.072 \\
\hline 42 & 14 & 14 & 14 & 0.00 & $=$ & Null & 0.074 & 0.062 & 0.064 & 0.070 & 0.059 & 0.058 & 0.071 & 0.073 & 0.061 \\
\hline 30 & 10 & 10 & 10 & 0.00 & $\neq$ & Null & 0.124 & 0.085 & 0.075 & 0.216 & 0.138 & 0.070 & 0.214 & 0.146 & 0.066 \\
\hline 36 & 12 & 12 & 12 & 0.00 & $\neq$ & Null & 0.116 & 0.073 & 0.060 & 0.186 & 0.123 & 0.076 & 0.176 & 0.114 & 0.067 \\
\hline 42 & 14 & 14 & 14 & 0.00 & $\neq$ & Null & 0.103 & 0.065 & 0.058 & 0.159 & 0.109 & 0.070 & 0.156 & 0.112 & 0.065 \\
\hline 30 & 5 & 10 & 15 & 0.41 & $\neq$ & + & 0.223 & 0.155 & 0.095 & 0.095 & 0.090 & 0.089 & 0.042 & 0.043 & 0.036 \\
\hline 36 & 6 & 12 & 18 & 0.41 & $\neq$ & + & 0.109 & 0.077 & 0.067 & 0.026 & 0.017 & 0.017 & 0.035 & 0.035 & 0.030 \\
\hline 42 & 7 & 14 & 21 & 0.41 & $\neq$ & + & 0.097 & 0.067 & 0.059 & 0.028 & 0.025 & 0.025 & 0.034 & 0.038 & 0.028 \\
\hline 30 & 15 & 10 & 5 & 0.41 & $\neq$ & - & 0.429 & 0.283 & 0.171 & 0.196 & 0.118 & 0.100 & 0.281 & 0.248 & 0.243 \\
\hline 36 & 18 & 12 & 6 & 0.41 & $\neq$ & - & 0.207 & 0.118 & 0.104 & 0.177 & 0.097 & 0.082 & 0.275 & 0.283 & 0.260 \\
\hline 42 & 21 & 14 & 7 & 0.41 & $\neq$ & - & 0.166 & 0.092 & 0.082 & 0.292 & 0.182 & 0.112 & 0.254 & 0.256 & 0.235 \\
\hline
\end{tabular}

Note. BW, SW and KR = methods for calculating the degrees of freedom (Between-Within, Satterthwaite and KenwardRoger) In bold = liberal; in italics = conservative 